Article

\title{
Nanoscale Phase Evolution during Continuum Decomposition of Fe-Cr Alloys
}

\author{
Yongsheng Li * (D), Lihui Zhu, Chengwei Liu and Shujing Shi \\ School of Materials Science and Engineering, Nanjing University of Science and Technology, Nanjing 210094, \\ China; zlhqjulie@163.com (L.Z.); cwliu16@163.com (C.L.); ssj3677@163.com (S.S.) \\ * Correspondence: ysli@njust.edu.cn; Tel.: +86-25-84315159
}

Received: 14 November 2017; Accepted: 13 December 2017; Published: 15 December 2017

\begin{abstract}
The continuum decomposition of the $\mathrm{Fe}-\mathrm{Cr}$ alloys from initial phase separation to steady-state coarsening with concentrations varying from 25 at \% $\mathrm{Cr}$ and 30 at $\% \mathrm{Cr}$ to 33 at $\% \mathrm{Cr}$ aged at $750 \mathrm{~K}$ was studied by utilizing three-dimensional phase-field simulations. The dynamic stages of separation of nanoscale $\mathrm{Cr}$-enriched $\alpha^{\prime}$ phase were distinguished by the evolution of the volume fraction, particle number density and the average particle radius of the $\alpha^{\prime}$ phase. The stage of steady-state coarsening was characterized with an equilibrium volume fraction and decreasing particle number density. The coarsening rate constant by linear fitting of the cube of average radius and aging time shows an increase with the increasing $\mathrm{Cr}$ concentration. The time exponents decrease from the growth and coarsening stage to the steady-state coarsening stage and show a dependence on the particles number density at different concentrations. The quantitative evolutions of $\alpha^{\prime}$ phase via nucleation growth and spinodal decomposition are theoretically helpful for understanding the microstructure evolution with aging time in Fe-Cr alloys.
\end{abstract}

Keywords: phase decomposition; Fe-Cr alloys; phase-field

\section{Introduction}

Fe-Cr alloys, the basic component of duplex stainless-steel (DSS), have exhibited excellent mechanical properties at high temperatures. As a structural material, high-Cr DSS has been used in nuclear power plants [1-3]. The excellent combination of mechanical properties and corrosion resistance of DSS is obtained from the balanced amount of ferrite and austenite in the microstructure. However, $\mathrm{Fe}-\mathrm{Cr}$ alloys are susceptible to embrittlement at aging temperatures ranging from $300-500{ }^{\circ} \mathrm{C}$ [4-6] or under radiation exposure [7]. This embrittlement is attributed to the spinodal decomposition of the solid state into an ultrafine mixture of $\mathrm{Cr}$-enriched and Fe-enriched phases. The separation of the Cr-enriched phase occurs rapidly at the early stages of aging, which has been demonstrated by concentration wavelength and hardness variations of $\mathrm{Fe}-\mathrm{Cr}$ alloys [8]. The composition is a dominant factor for the decomposition kinetics [9]. Therefore, the phase separation dynamics in $\mathrm{Fe}-\mathrm{Cr}$ alloys are potentially useful for predication of the morphology evolution and property change, and much attention has been focused on this question [10-15].

The separation of the Cr-enriched phase also can occur via the nucleation and growth in Fe-Cr alloys with low $\mathrm{Cr}$ concentration $[16,17]$. The Mössbauer spectroscopy also demonstrated the decomposition via nucleation and growth in $\mathrm{Fe}-24$ at $\% \mathrm{Cr}$ alloy at $475{ }^{\circ} \mathrm{C}$ [18]. Atom probe tomography (APT) results showed that the $\alpha^{\prime}$ phase separation is by means of non-classical nucleation and growth in $\mathrm{Fe}-20$ at $\% \mathrm{Cr}$ alloy aged at $773 \mathrm{~K}$ from 50-1067 $\mathrm{h}$ [3]. A transient coarsening regime was observed for the overlap of the nucleation, growth and coarsening, and the steady-state coarsening was not observed for an aging time of $1067 \mathrm{~h}$, while a linear evolution of the cube of the mean particle radius was presented. The Ising model demonstrates that there was a gradual transition from nucleation and 
growth to spinodal decomposition at the spinodal line [19], while a sharp change was predicted by the Cahn-Hilliard theory of spinodal decomposition [20]. Xiong et al. [21] summarized the decomposition mechanisms of the Fe-Cr alloys for the experimental and theoretical results, which show overlapped regions for the nucleation growth and spinodal decomposition. In addition, their three dimensional atom probe tomograph (3D-APT) results showed that a transition region from nucleation and growth to spinodal decomposition exists in the composition regions from $24-36.3$ at $\% \mathrm{Cr}$ [22]. Therefore, the transition mechanism from nucleation and growth to spinodal decomposition in $\mathrm{Fe}-\mathrm{Cr}$ alloys is theoretically interesting and practicably important.

In addition, the dynamics of growth and coarsening of the $\alpha^{\prime}$ phase is also indispensable for quantitative analysis and morphology prediction during aging. An atomic-scale analysis of phase decomposition in a thermally aged $\mathrm{Fe}-25$ at $\% \mathrm{Cr}$ alloy at $500{ }^{\circ} \mathrm{C}$ using a 3DAP and atomistic kinetics Monte Carlo (AKMC) simulation was presented, in which the fitting of the length scale and time, $L^{3} \sim t$ and $L \sim t^{1 / 3}$ both presented a linear relationship [23]. Miller et al. [24-26] studied the kinetics of early stage phase decomposition and the spinodal morphology in $\mathrm{Fe}-\mathrm{Cr}$ alloys. The microstructure scale simulated by the Cahn-Hilliard-Cook equation showed a time exponent close to the value of $1 / 3$ of that predicted by Lifshitz-Slyozov-Wagner (LSW) $[27,28]$ theory for the coarsening of isolated precipitates. However, their experimental fitting yielded a time exponent of $0.25 \pm 0.03$, and the Monte Carlo simulation fitted a power law relationship with a time exponent of $0.21 \pm 0.03$ [25]. Rogers et al. [29] used finite difference methods to study a 2D percolating spinodal system with a continuous order parameter, and found that the domains coarsen with a time exponent of $1 / 3$ at a late time independent of thermal noise. The separation of the $\alpha^{\prime}$ phase by spinodal decomposition was studied in a Fe- 42 at \% Cr alloy at $700 \mathrm{~K}, 725 \mathrm{~K}$ and $750 \mathrm{~K}$, the results showed an increased growth and coarsening rate with the aging temperature increases [30].

However, the continuum dynamics of $\alpha^{\prime}$ phase from initial separation to growth and coarsening via nucleation and growth to spinodal decomposition with $\mathrm{Cr}$ concentration increasing need a theoretical clarification in the $\mathrm{Fe}-\mathrm{Cr}$ alloys. In this work, the alloys inside the regions of nucleation and growth, near the spinodal line and inside the spinodal region, were chosen to ensure phase separation from nucleation and growth to spinodal decomposition. The early stage evolving for the minute nano-scale particles in the $\mathrm{Fe}-\mathrm{Cr}$ system is a notable challenge [10], so we utilized a three dimensional (3D) phase-field model [31,32] to investigate the evolution of the morphology, the time exponent of the length scale of steady-state coarsening and the particle number density of $\alpha^{\prime}$ phase in Fe-25 at \% Cr, $\mathrm{Fe}-30$ at \% $\mathrm{Cr}$ and $\mathrm{Fe}-33$ at \% $\mathrm{Cr}$ alloys aged at $750 \mathrm{~K}$. The stages of phase separation from the initial separation to growth and steady-state coarsening were distinguished by the temporal variation of the particle number density, the volume fraction and the average radius of $\alpha^{\prime}$ phase.

\section{Phase-Field Model and Calculation Methods}

\subsection{Phase-Field Model}

The composition evolution in Fe-Cr alloys can be described by the Cahn-Hilliard diffusion equation [33]

$$
\frac{\partial c(\mathrm{r}, t)}{\partial t}=V_{m} \nabla \cdot\left[M \nabla\left(\frac{\delta F}{\delta c(\mathrm{r}, t)}\right)\right]
$$

where $c$ is the nominal composition of $\mathrm{Cr}, M$ is the chemical mobility given by Darken's equation $[34,35]$ $M=\frac{1}{V_{m}}\left[c M_{\mathrm{Fe}}+(1-c) M_{\mathrm{Cr}}\right] c(1-c)$, where $M_{\mathrm{Fe}}$ and $M_{\mathrm{Cr}}$ are the atomic mobility of Fe and $\mathrm{Cr}$, respectively, which are related to the diffusivity through Einstein's relation $M_{i}=D_{i} / R T$, where $i$ denotes the element $\mathrm{Fe}$ or $\mathrm{Cr}, D_{i}$ is the diffusion coefficient, and the diffusion constant for $\mathrm{Fe}$ and $\mathrm{Cr}$ are $1.2 \times 10^{-4}$ and $2.0 \times 10^{-5}$, respectively, the activation energy is $294 \mathrm{~kJ} \cdot \mathrm{mol}^{-1}$ for Fe and $308 \mathrm{~kJ} \cdot \mathrm{mol}^{-1}$ for $\mathrm{Cr}[36,37]$. Recently, the mobility matrix related with the local composition was utilized in the phase-field model for multi-component alloys [38], while the calculation is more complex than the linear variation between the elements. 
The total free energy $F$ of Fe-Cr alloys includes the chemical free energy, interfacial energy and elastic strain energy induced by the composition inhomogeneity between the $\alpha$ and $\alpha^{\prime}$ phase, and can be expressed as [39]:

$$
F=\int_{V}\left\{\frac{1}{V_{m}}\left[G+\frac{1}{2} \kappa(\nabla c)^{2}\right]+E_{e l}\right\} d V
$$

where $V_{m}$ is the molar volume of the alloy, $\kappa$ is the gradient energy coefficient, $E_{e l}$ is the elastic energy density per unit volume, and $G$ is the molar Gibbs free energy given by [40]

$$
G=(1-c) G_{\mathrm{Fe}}^{0}+c G_{\mathrm{Cr}}^{0}+L_{\mathrm{FeCr}} c(1-c)+R T[c \ln c+(1-c) \ln (1-c)]+G_{m}
$$

where $G_{\mathrm{Fe}}^{0}$ and $G_{\mathrm{Cr}}^{0}$ are the energies of the pure elements [41], $R$ is the gas constant, $T$ is the absolute temperature, $L_{\mathrm{FeCr}}$ is the interaction parameter between $\mathrm{Fe}$ and $\mathrm{Cr}$, and is adopted as $L_{\mathrm{FeCr}}=20,500-$ $9.68 \mathrm{~T}\left(\mathrm{~J} \cdot \mathrm{mol}^{-1}\right)$ [42], $G_{m}$ is the magnetic ordering contribution to the Gibbs free energy, and its expression can refer to the literature $[15,40]$.

The concentration gradient coefficient for the nearest neighbor interactions is expressed by $\kappa=\frac{1}{6} r_{0}^{2} L_{\mathrm{FeCr}}$ [36], where $r_{0}$ is the interatomic distance at a stress-free state and changes with composition obey the Vergard's law. It should be noted that the composition effects are neglected in the gradient coefficient, which may have an influence on the interface width [43,44].

The free energy of Fe-Cr alloy including the Gibbs free energy $G$ and elastic strain energy at $750 \mathrm{~K}$ is plotted in Figure 1, where the compositions for phase separation and spinodal decomposition are labelled in the curve, and points $\mathbf{a}$ and $\mathbf{b}$ are the composition boundary for phase separation and spinodal decomposition at $750 \mathrm{~K}$, respectively. The elastic strain energy density per unit volume can be calculated by $E_{e l}=\frac{1}{2} C_{i j k l} \varepsilon_{i j}^{\mathrm{el}} \mathrm{e}_{k l}^{\mathrm{el}}$. For the detailed solution for elastic strain $\varepsilon_{i j}^{\mathrm{el}}$, refer to the literature $[13,45,46]$.

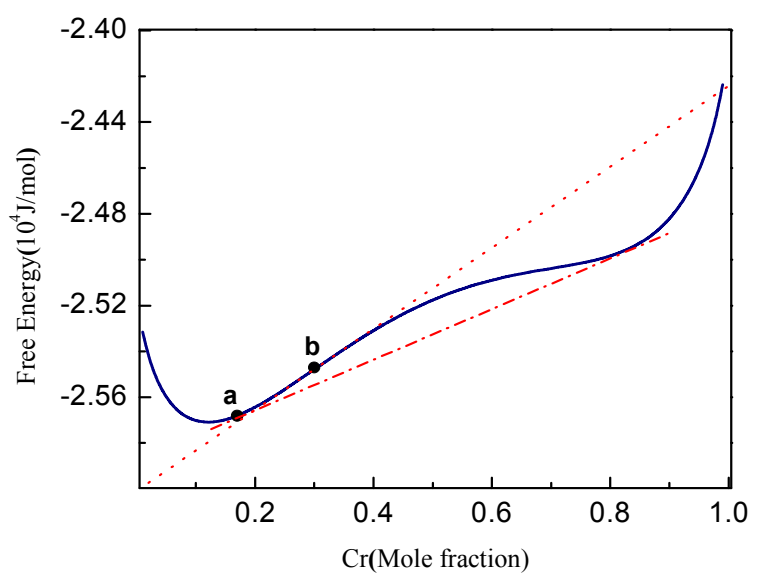

Figure 1. Free energy of the $\mathrm{Fe}-\mathrm{Cr}$ alloy at $750 \mathrm{~K}$, point a with $\mathrm{Cr}$ concentration $c_{\mathrm{Cr}}=0.17$ delegates the boundary composition of phase separation, point $\mathbf{b}\left(c_{\mathrm{Cr}}=0.30\right)$ delegates the critical composition of spinodal decomposition. The dotted line is the tangent through the spinodal boundary and dash-dotted line is the tangent of equilibrium composition.

\subsection{Numerical Calculation}

By substituting Equation (2) into Equation (1) and performing the dimensionless, we can calculate numerically by using the semi-implicit Fourier spectrum method $[47,48]$ with a time step of $\Delta t^{*}=0.001$. $T_{\mathrm{c}}=900 \mathrm{~K}[21,24]$ is the critical temperature of spinodal decomposition of the alloy. The lattice parameters are $a_{\mathrm{Fe}}=0.2866 \mathrm{~nm}$ and $a_{\mathrm{Cr}}=0.2882 \mathrm{~nm} \mathrm{[49],} \mathrm{the} \mathrm{dimensionless} \mathrm{grid} \mathrm{size} \mathrm{is} \mathrm{chosen}$ as $\Delta x^{*}=\Delta y^{*}=\Delta z^{*}=1.0$, and the simulation cell size is $128 \Delta x^{*} \times 128 \Delta y^{*} \times 128 \Delta z^{*}$. The elastic constants of Fe are approximately chosen as $C_{11}^{\mathrm{Fe}}=197, C_{12}^{\mathrm{Fe}}=128$ and $C_{44}^{\mathrm{Fe}}=107 \mathrm{GPa}$ at $773 \mathrm{~K}$ [50]; those for elemental $\mathrm{Cr}$ are $C_{11}^{\mathrm{Cr}}=358, C_{12}^{\mathrm{Cr}}=106$ and $C_{44}^{\mathrm{Cr}}=95 \mathrm{GPa}$ at $650 \mathrm{~K}$ [51]. The chemical mobility $M$ 
is updated for each calculation step with the iterative temporal changes in composition throughout the simulation.

A random thermal fluctuation (Langevin noise) at a magnitude of [ $-0.002,0.002]$ is introduced into the initial composition in the simulation to trigger the phase separation, and an iteration of the thermal fluctuation is performed for the alloys in the metastable regions (between point $\mathbf{a}$ and $\mathbf{b}$ of Figure 1) of nucleation and growth (Fe-25 at \% Cr) or near the boundary of spinodal decomposition (Fe-30 at \% Cr). It should be noted that the thermal fluctuation should have a minimum magnitude for triggering the phase decomposition, as a large fluctuation may affect the initial particle number and the particles radius. As we know, there are different approaches to simulate the nucleation in the phase field simulation, such as the Langevin noise method and the explicit nucleation method [52-54]. The other numerical algorithms for nucleation problems include computing saddle points and minimum energy path [54]. The merits and drawbacks of these methods are discussed in the literature [52-54], in addition, the implementation of these new approaches is not straight forward and is computationally complex.

\section{Results and Discussion}

\subsection{Phase Separation in Metastable Regions}

The morphology evolution of the Cr-enriched $\alpha^{\prime}$ phase in the Fe-25 at \% Cr alloy aged at $750 \mathrm{~K}$ is presented in Figure 2, where the red regions depict the $\mathrm{Cr}$-enriched $\alpha^{\prime}$ phase and the blue regions depict the Fe-enriched $\alpha$ phase. For the alloy locates in the metastable region, the initial thermal fluctuation was added for an iteration of 400 time steps, and was removed when the system was able to develop automatically. It can be seen from Figure $2 \mathrm{a}, \mathrm{b}$ that some of the initially emerging $\mathrm{Cr}$-enriched clusters develop into the $\alpha^{\prime}$ phase as the aging progresses. There are deep blue regions of low $\mathrm{Cr}$ concentration around the $\alpha^{\prime}$ phase, which is caused by the $\mathrm{Cr}$ atom diffusing from the matrix $\alpha$ to support the growth of $\alpha^{\prime}$ phase. Then, the $\alpha^{\prime}$ phase precipitates gradually from the matrix and its number increases, as shown in Figure 2b,c. The following coarsening of the spherical $\alpha^{\prime}$ phase occurs through individual coarsening for the separated particles and coalescence coarsening for some neighbor particles, as shown in Figure $2 \mathrm{~d}$.

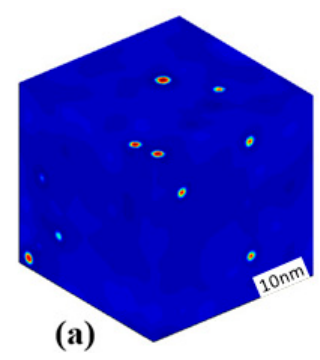

(a)

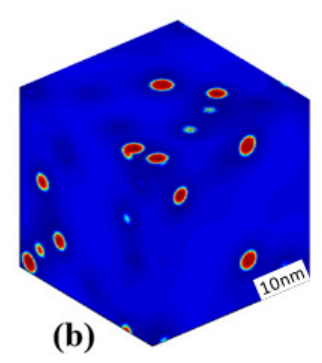

(b)

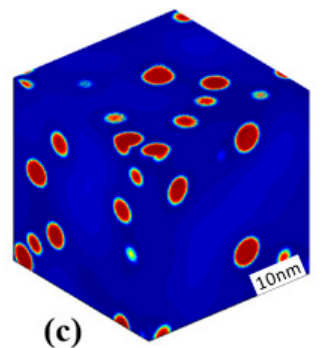

(c)

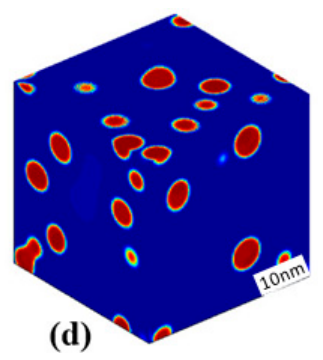

(d)

Figure 2. 3D morphology evolution of the Cr-enriched $\alpha^{\prime}$ phase in the Fe-25 at \% Cr alloy aged at $750 \mathrm{~K}$, (a) $t=46 \mathrm{~h}$; (b) $t=115 \mathrm{~h}$; (c) $t=5390 \mathrm{~h}$; (d) $t=6773 \mathrm{~h}$.

The spherical $\alpha^{\prime}$ particles in the Fe-25 at \% $\mathrm{Cr}$ alloy aged at $750 \mathrm{~K}$ have an average radius of approximately $3.4 \mathrm{~nm}$ after aging for $6773 \mathrm{~h}$. The atom probe tomography (APT) result for the $\alpha^{\prime}$ radius is approximately $2.53 \pm 0.51 \mathrm{~nm}$ in Fe-20 at \% $\mathrm{Cr}$ alloy aged at $773 \mathrm{~K}$ for $1067 \mathrm{~h}$ [3]. The characteristic length of $\alpha^{\prime}$ is $3 \mathrm{~nm}$ in a thermally aged Fe-25 at \% Cr alloy at $500{ }^{\circ} \mathrm{C}$ for $240 \mathrm{~h}$ detected by the 3D atom probe (3DAP) [23]. Lopez-Hirata et al. studied the phase decomposition of a Fe-40 at \% Cr alloy aged at $475{ }^{\circ} \mathrm{C}$ and $500{ }^{\circ} \mathrm{C}$ [55], and their results revealed a $\mathrm{Cr}$-enriched phase with a size of less than $10 \mathrm{~nm}$. The radius of the $\alpha^{\prime}$ phase is approximately $4 \mathrm{~nm}$ in Fe-40 at \% $\mathrm{Cr}$ alloy aged at $773 \mathrm{~K}$ for $500-750 \mathrm{~h}$ detected by a TEM experiment [8]. Thus, the simulated morphologies of $\alpha^{\prime}$ phase are consistent with the previous experimental results.

The separation dynamics of the $\alpha^{\prime}$ phase in Fe-25 at \% Cr alloy aged at $750 \mathrm{~K}$ were analyzed by the temporal variation of volume fraction, particle number density and the average particle radius of the 
$\alpha^{\prime}$ phase. The particle number density $N_{\mathrm{d}}$ is defined by the $\alpha^{\prime}$ phase number per unit volume, and the average particle radius $<R>$ is an average radius of an approximate spherical shape with a volume $V$ of the $\alpha^{\prime}$ phase, $<R>=\frac{1}{N_{\mathrm{p}}} \sum_{i=1}^{N_{\mathrm{p}}}(3 V / 4 \pi)^{1 / 3}$, where $N_{\mathrm{p}}$ is the total number of the $\alpha^{\prime}$ phases. As shown in Figure 3, the separation of the $\alpha^{\prime}$ phase can be separated into four stages: (I) nucleation of the $\alpha^{\prime}$ phase at the initial phase separation; (II) nucleation and growth; (III) concurrent growth and coarsening once the maximum value of $N_{\mathrm{d}}$ is achieved; (IV) steady-state coarsening with a stable volume fraction. The time exponent at the steady-state coarsening is calculated by fitting the relationships of $N_{\mathrm{d}} \sim t^{\mathrm{m}}$ and the $<R>\sim t^{n}$, they are $m=-0.46$ and $n=0.16$.

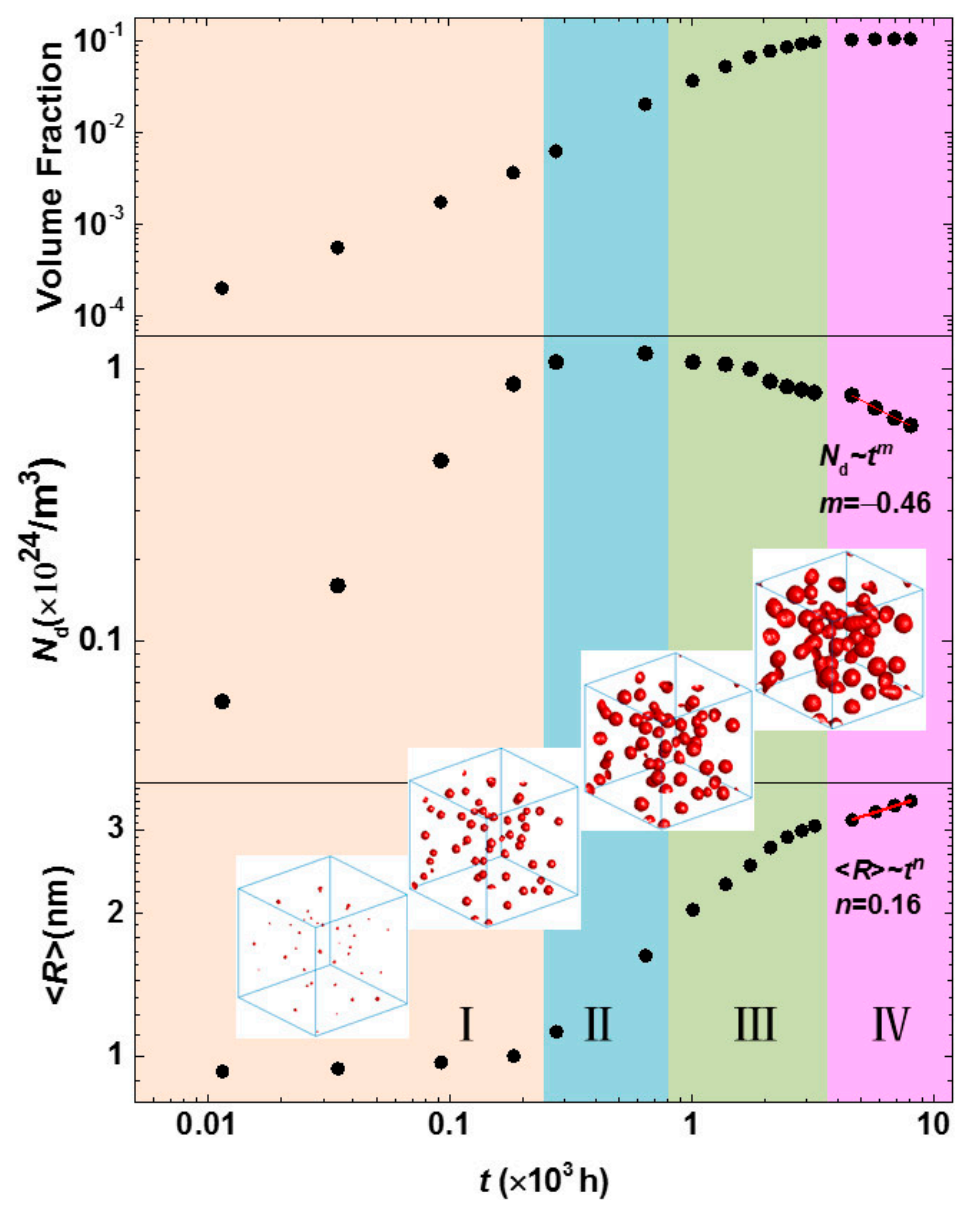

Figure 3. The temporal evolution of the volume fraction, particle number density and the average particle radius of the $\mathrm{Cr}$-enriched $\alpha^{\prime}$ phase in the $\mathrm{Fe}-25$ at \% $\mathrm{Cr}$ alloy aged at $750 \mathrm{~K}$. The inserted morphology evolution is for $3 \mathrm{D} \alpha^{\prime}$ particles from initial growth to coarsening.

The time exponent 0.16 of the steady-state coarsening is less than $1 / 3$ from classical LSW theory $[26,27]$. However, the LSW theory is suitable under the conditions of dilute solutions with near-zero volume fractions when there are no elastic interactions between precipitates. It is implicit that the evaporation-condensation mechanism, i.e., Ostwald ripening, is operative in LSW theory. In addition, the fitted exponent in the steady-state coarsening has a decrease in the early growth and coarsening stage with the exponent 0.41 , and the limited particles number also affects the statistic. Miller also found a small time exponent $0.25 \pm 0.03$ by fitting their experimental results [25]. Pareige did not fit the time exponent when studying the precipitation of the $\alpha^{\prime}$ phase in Fe-Cr alloys with 3DAP; however, they demonstrated a linear relationship between the domain scale $L$ and time $t, L^{3} \sim t$ and $L \sim t^{1 / 3}$ were both presented [23]. The cube of the average particle size $<R>^{3}$ and time $t$ were fitted 
at the steady-state coarsening stage, as shown in Figure 4, which also shows a linear relationship with the coarsening rate constant $k=2.8 \times 10^{-3}$ independent of the time exponent of $n=0.16$. Therefore, the linear fitting of $\left\langle R>^{3} \sim t\right.$ does not imply the time exponent $n=1 / 3$. A time exponent $n$ deduced from the average radius and time $<R>\sim t^{n}$ indicates the dynamics of phase precipitation, which also showed in the nickel-based alloys [56].

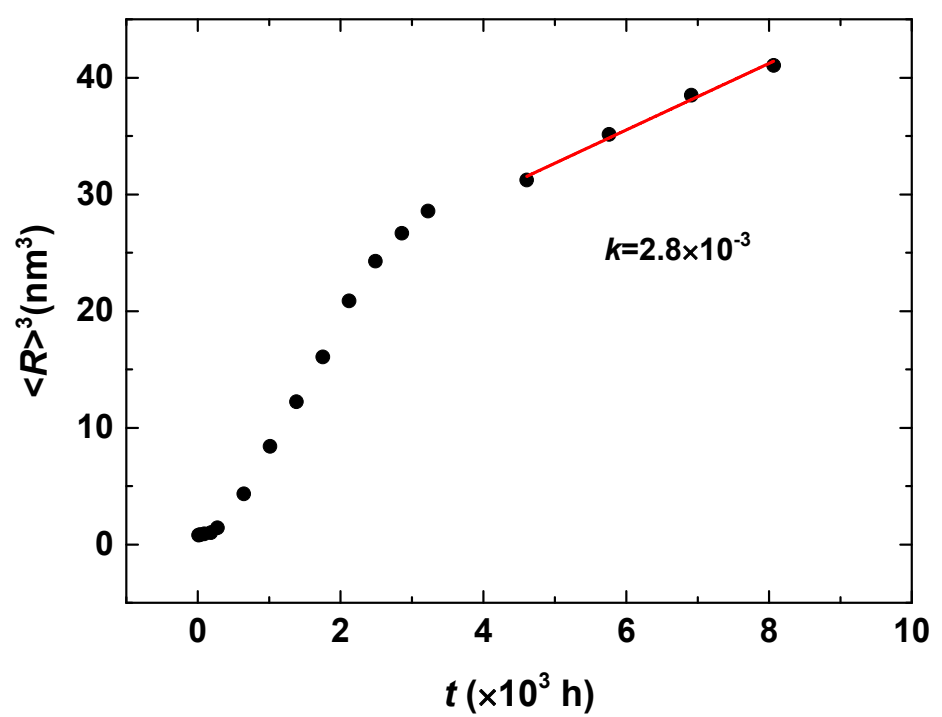

Figure 4. The temporal evolution of the cube of the average particle radius of the Cr-enriched $\alpha^{\prime}$ phase at steady-state coarsening in the $\mathrm{Fe}-25$ at $\% \mathrm{Cr}$.

\subsection{Phase Separation Near the Spinodal Boundary}

Figure 5 displays the morphology evolution of the $\alpha^{\prime}$ phase in the Fe-30 at \% Cr alloy aged at $750 \mathrm{~K}$, which is near the point $b$ of Figure 1 . In this analysis, the magnitude of initial thermal fluctuation is [-0.002, 0.002], and the length of time steps is the same as those of Figure 2, but the number of iterations of thermal fluctuation is reduced to 100 time steps. The iterative addition of thermal fluctuation for the precipitation indicates that nucleation and growth still happen for alloys near the spinodal line. The initial morphology of the $\alpha^{\prime}$ phases shown in Figure 5a is similar to that of Figure 2a, where the Cr-enriched particles emerge separately. Then, the spherical $\alpha^{\prime}$ phases grow and coarsen continuously, as shown in Figure $5 b-d$, in which the coalescence coarsening and Ostwald ripening are both present and some neighboring $\alpha^{\prime}$ particles interconnect each other and form a worm shape. As the coarsening progresses, the distance between the particles is enlarged, the diffusion distance of $\mathrm{Cr}$ to the $\alpha^{\prime}$ phase increases, and the Ostwald ripening becomes more obvious, as shown in Figure $5 \mathrm{c}, \mathrm{d}$. Therefore, the coarsening of the $\alpha^{\prime}$ phase in the Fe-30 at \% $\mathrm{Cr}$ alloy aged at $750 \mathrm{~K}$ prefers the coalescence coarsening at initial stages but is dominated by the Ostwald ripening at later stages.

Figure 6 shows the temporal dynamics evolution of the volume fraction, particle number density and the average particle radius of the $\alpha^{\prime}$ phase. The dynamics of phase separation in $\mathrm{Fe}-30 \mathrm{at} \% \mathrm{Cr}$ alloy aged at $750 \mathrm{~K}$ show three stages: (I) fast precipitation and concurrent growth of the $\alpha^{\prime}$ phase with an increased particle number, volume fraction and radius; (II) slow precipitation and growth before the maximum $N_{\mathrm{d}}$ is achieved; and (III) steady-state coarsening, in which the volume fraction has a steady value. The dynamics exponents for the particle number density $N_{\mathrm{d}} \sim t^{\mathrm{m}}$ is $m=-0.49$ and for the average particle radius $\left\langle R>\sim t^{n}\right.$ is $n=0.18$. The magnitudes of the time exponents are close to those of $\mathrm{Fe}-25$ at $\% \mathrm{Cr}$ alloy aged at $750 \mathrm{~K}$. The cube of the average particle radius $\left\langle R>^{3}\right.$ and time $t$ was also fitted with a linear function for the Fe-30 at \% $\mathrm{Cr}$ alloys aged at $750 \mathrm{~K}$ at the steady-state coarsening stage, the coarsening rate constant is $k=1.7 \times 10^{-2}$. The variation of coarsening rate constants indicates the increased coarsening rate as the $\mathrm{Cr}$ concentration increases, as shown in Table 1. 


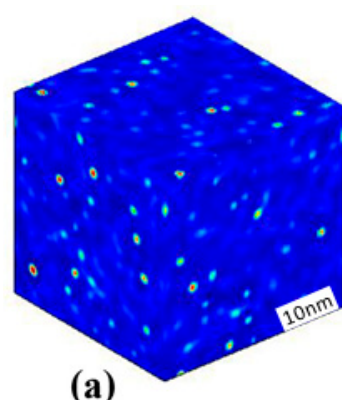

(a)

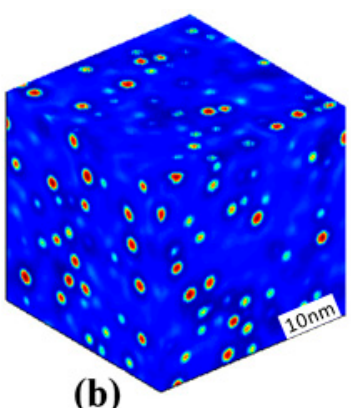

(b)

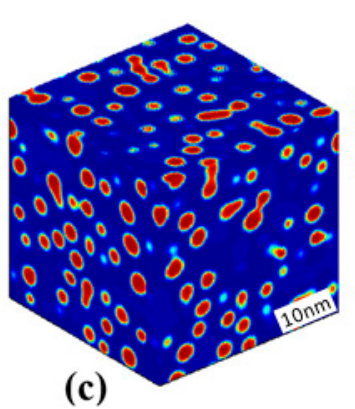

(c)

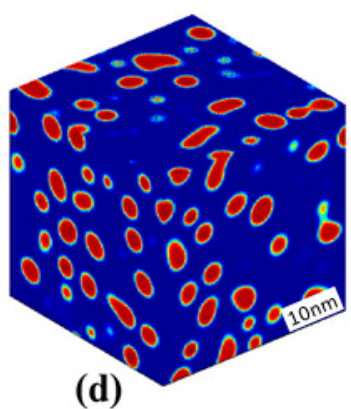

(d)

Figure 5. 3D morphology of the Cr-enriched $\alpha^{\prime}$ phase in the $\mathrm{Fe}-30$ at \% $\mathrm{Cr}$ alloy aged at $750 \mathrm{~K}$, (a) $t=70 \mathrm{~h}$; (b) $t=138 \mathrm{~h}$; (c) $t=691 \mathrm{~h}$; (d) $t=2995 \mathrm{~h}$.

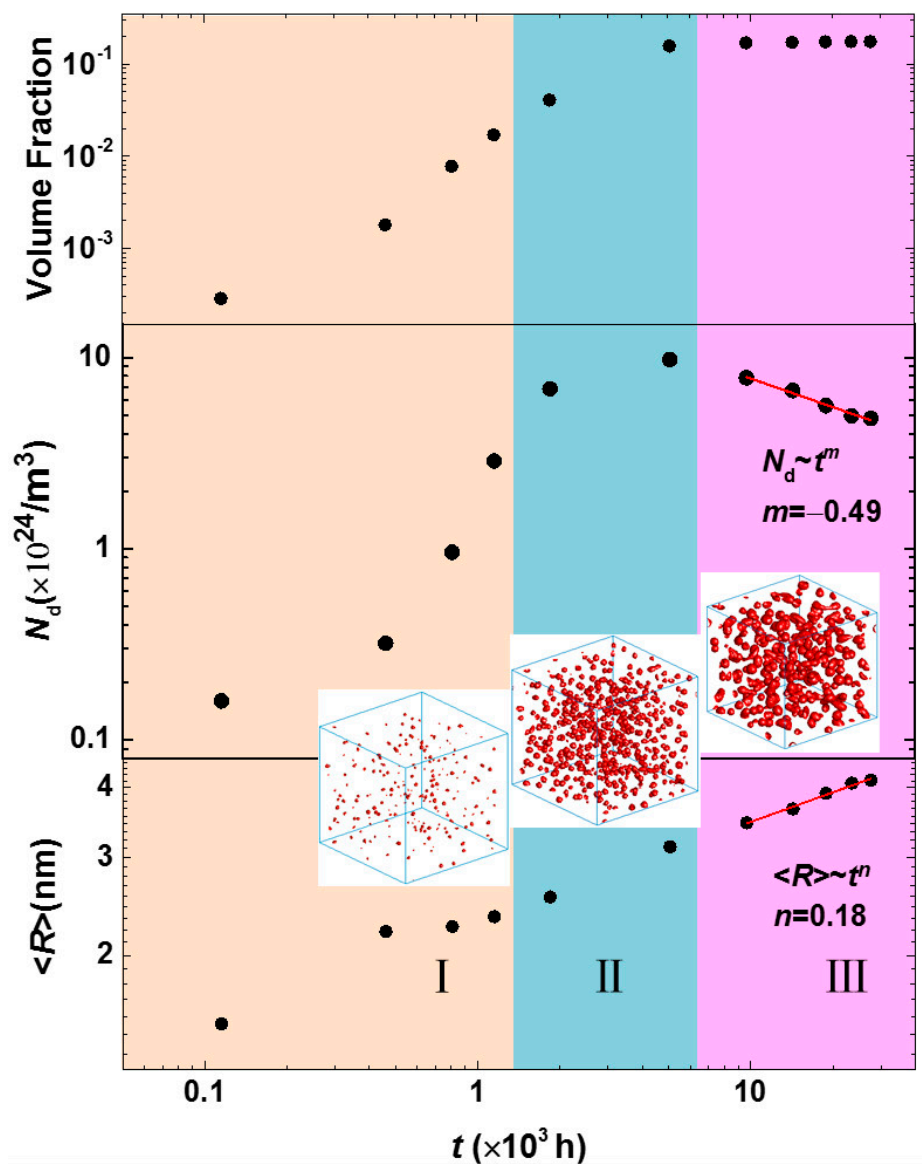

Figure 6. The temporal evolution of the volume fraction, particle number density and the average particle radius of the Cr-enriched $\alpha^{\prime}$ phase in the Fe-30 at \% $\mathrm{Cr}$ alloy aged at $750 \mathrm{~K}$.

Table 1. Coarsening rate constants $k$ and time exponents for the average radius and particle number density of the $\alpha^{\prime}$ phase in Fe-Cr alloys aged at $750 \mathrm{~K}$.

\begin{tabular}{cccc}
\hline Cr (at \%) & 25 & 30 & 33 \\
\hline$k$ & $2.8 \times 10^{-3}$ & $1.7 \times 10^{-2}$ & $2.1 \times 10^{-2}$ \\
$n$ & 0.16 & 0.18 & 0.18 \\
$m$ & -0.46 & -0.49 & -0.48 \\
\hline
\end{tabular}




\subsection{Phase Separation in Spinodal Decomposition Region}

Figure 7 displays the morphology evolution of the $\alpha^{\prime}$ phase in the Fe-33 at \% $\mathrm{Cr}$ alloy aged at $750 \mathrm{~K}$, where more $\alpha^{\prime}$ particles precipitate, as shown in Figure 7a, than in any of the alloys in or near the regions of nucleation and growth. For this alloy, the magnitude of initial thermal fluctuation is the same as Fe-30 at $\% \mathrm{Cr}$ alloy aged at $750 \mathrm{~K}$ while without iterations. As the precipitation and growth of the $\alpha^{\prime}$ particles progresses, the connection of neighbor particles progresses simultaneously, as shown in Figure 7a,b. Then, Ostwald ripening accompanied by coalescence coarsening occurs in Figure 7c,d as the particle distance increases. Therefore, the coarsening of the $\alpha^{\prime}$ phase in the Fe-33 at \% Cr alloy aged at $750 \mathrm{~K}$ is dominated by the coalescence coarsening of the initial stages followed by concurrent coalescence coarsening and Ostwald ripening at later stages. Due to the coalescence of the $\alpha^{\prime}$ particles, a worm-shaped $\alpha^{\prime}$ phase is present at the aging time $t=1152 \mathrm{~h}$.

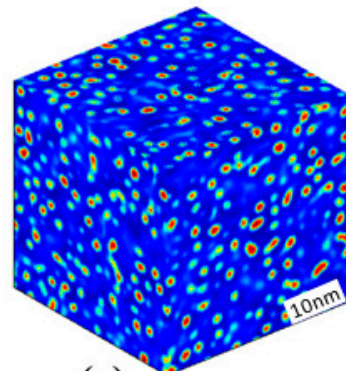

(a)

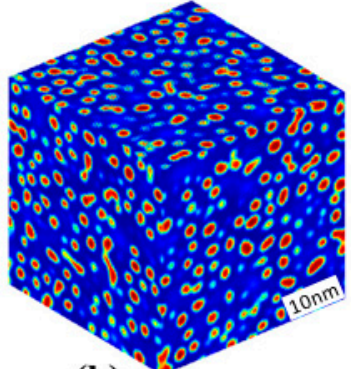

(b)

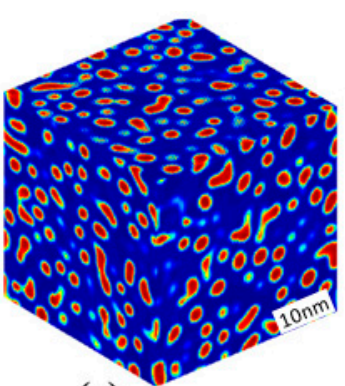

(c)

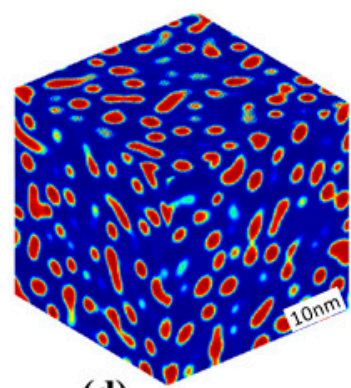

(d)

Figure 7. 3D morphology of the Cr-enriched $\alpha^{\prime}$ phase in the $\mathrm{Fe}-33$ at \% $\mathrm{Cr}$ alloy aged at $750 \mathrm{~K}$, (a) $t=70 \mathrm{~h}$; (b) $t=138 \mathrm{~h}$; (c) $t=506 \mathrm{~h}$; (d) $t=1152 \mathrm{~h}$.

The time exponents were also calculated by fitting the particle number density and the average particle radius of steady-state coarsening of the $\mathrm{Cr}$-enriched $\alpha^{\prime}$ phase in the $\mathrm{Fe}-33$ at $\% \mathrm{Cr}$ alloy aged at $750 \mathrm{~K}$. Table 1 shows the time exponents of the average radius and particle number density of the $\alpha^{\prime}$ phase with different compositions. The time exponents for the average radius are less than the $1 / 3$ expected from classical LSW theory at $750 \mathrm{~K}$. The coarsening time exponent increases as the $\mathrm{Cr}$ concentration increases from 25 at $\%$ to 33 at $\%$ at $750 \mathrm{~K}$. The present simulation includes the elastic interactions between the $\alpha$ and $\alpha^{\prime}$ solid phases with a large volume fraction. In addition, the higher particle number density has a smaller particle distance for the high concentration or low temperature aging, which favors the coalescence coarsening and Ostwald ripening via short-distance diffusion. Therefore, the coarsening time exponents are increased as the particle number density changes from $1.13 \times 10^{24}$ to $9.7 \times 10^{24}$ and $2.5 \times 10^{25} \mathrm{~m}^{-3}$ as the $\mathrm{Cr}$ concentration increases at $750 \mathrm{~K}$. As a result, the coarsening time exponent of the $\alpha^{\prime}$ phase depends on the composition that relates with the particle number density.

Additionally, there are some experimental results that show the coarsening time exponent is less than 1/3 [29,57-59]. The autocorrelation function from the energy compensated atomic probe in Hyde's results also showed a time exponent of $\sim 0.21$, and the PoSAP (position-sensitive atom probe) time exponent was $\sim 0.25$ in Fe-30 at \% Cr alloy at $773 \mathrm{~K}$ [25]. While Hyde's numerical results simulated by the Cahn-Hilliard-Cook equation follow a power law close to the $1 / 3$ of the classical LSW theory, it should be noted that the elastic energy and magnetic energy are not considered in the Cahn-Hilliard-Cook equation [24].

As a result of the phase separation in the Fe-Cr alloys from nucleation and growth to spinodal decomposition, the coarsening time exponents of steady-state coarsening deduced by the $\left\langle R>\sim t^{n}\right.$ show values from 0.16 to 0.18 as the concentration changed from 0.25 to 33 at $\% \mathrm{Cr}$ aging at $750 \mathrm{~K}$. The high concentration alloy with 35 at $\% \mathrm{Cr}$ aging at $750 \mathrm{~K}$ has a time exponent 0.36 at $750 \mathrm{~K}$, the temperature dependent exponent is also shown in the $\mathrm{Fe}-35$ at \% Cr alloy [60]. The coarsening rate constant $k$ deduced from $\left\langle R>^{3} \sim k t\right.$ increases with the concentration, which is attributed to the short 
distances of diffusion required at high concentrations. The statistic of simulation may include some shortcomings, such as the composition independent interface energy and the simplified mobility, which has an effect on the quantitative calculation of the coarsening time exponent. Therefore, further work using the abundant thermodynamic database and the diffusion coefficients is expected for the quantitative simulation.

\section{Conclusions}

The continuum separation dynamics and the morphology of nanoscale Cr-enriched $\alpha^{\prime}$ phase in $\mathrm{Fe}-\mathrm{Cr}$ alloys aged at $750 \mathrm{~K}$ were quantitatively investigated using three-dimensional phase-field simulations. The dynamic stages from the initial separation and growth to steady-state coarsening of $\alpha^{\prime}$ phase were distinguished by the temporal evolution of the volume fraction, particle number density and the average particle radius of the $\alpha^{\prime}$ phase, accompanied by the phase separation mechanisms of nucleation growth and spinodal decomposition deduced from the free energy curve.

The $\alpha^{\prime}$ phase proceeds through the stages of nucleation, nucleation and growth, growth and coarsening and steady-state coarsening for the mechanism of nucleation and growth. The phase decomposition is accelerated as the $\mathrm{Cr}$ concentration is increased. The time exponents of steady-state coarsening show an increase from 0.16 of $\mathrm{Fe}-25$ at \% $\mathrm{Cr}$ aged at $750 \mathrm{~K}$ (nucleation and growth) to 0.18 of $\mathrm{Fe}-33$ at \% $\mathrm{Cr}$ aged at $750 \mathrm{~K}$ (spinodal decomposition) and as the $\mathrm{Cr}$ concentration increases, the large particles number density results in the increased time exponent. Simultaneously, the fitting of the cube of average radius and time, $\left\langle R>^{3} \sim t\right.$, shows an increased coarsening rate constant with the alloy concentration increasing, as a result of the short distances of diffusion for high $\mathrm{Cr}$ concentrations alloy. The results for the continuum dynamics evolution are scientific and applicable to phase separation occurring via nucleation and growth and spinodal decomposition with variable compositions in the Fe-Cr alloys.

Acknowledgments: This work was supported by the National Natural Science Foundation of China (grant Number 51571122) and the Fundamental Research Funds for the Central Universities (grant Number 30916015107).

Author Contributions: Yongsheng Li performed the model and the program code for simulation, and wrote the manuscript. Lihui Zhu analyzed the data, Chengwei Liu and Shujing Shi performed the simulation.

Conflicts of Interest: No conflict of interest exists in the submission of this manuscript, and all authors have seen the manuscript and approved to submit to Materials.

\section{References}

1. Marshal, P. Austenitic Stainless Steels: Microstructure and Mechanical Properties; Elsevier Applied Science Publishers: Amsterdam, The Netherlands, 1984.

2. Klueh, R.L.; Nelson, A.T. Ferritic/martensitic steels for next-generation reactors. J. Nucl. Mater. 2007, 37, 137-152. [CrossRef]

3. Novy, S.; Pareige, P.; Pareige, C. Atomic scale analysis and phase separation understanding in a thermally aged Fe- 20 at.\% Cr alloy. J. Nucl. Mater. 2009, 384, 96-102. [CrossRef]

4. Sahu, J.K.; Krupp, U.; Ghosh, R.N.; Christ, H.J. Effect of $475^{\circ} \mathrm{C}$ embrittlement on the mechanical properties of duplex stainless steel. Mater. Sci. Eng. A 2009, 508, 1-14. [CrossRef]

5. Iacoviello, F.; Casari, F.; Gialanella, S. Effect of $475^{\circ} \mathrm{C}$ embrittlement on duplex stainless steels localized corrosion resistance. Corros. Sci. 2005, 47, 909-922. [CrossRef]

6. Pettersson, N.; Wessman, S.; Thuvander, M.; Hedström, P.; Odqvist, J.; Pettersson, R.F.A.; Hertzman, S. Nanostructure evolution and mechanical property changes during aging of a super duplex stainless steel at $300{ }^{\circ}$ C. Mater. Sci. Eng. A 2015, 647, 241-248. [CrossRef]

7. Senninger, O.; Soisson, F.; Martínez, E.; Nastar, M.; Fu, C.C.; Bréchet, Y. Modeling radiation induced segregation in iron-chromium alloys. Acta Mater. 2016, 103, 1-11. [CrossRef]

8. Soriano-Vargas, O.; Avila-Davila, E.O.; Lopez-Hirata, V.M.; Cayetano-Castro, N.; Gonzalez-Velazquez, J.L. Effect of spinodal decomposition on the mechanical behavior of Fe-Cr alloys. Mater. Sci. Eng. A 2010, 527, 2910-2914. [CrossRef] 
9. Miller, M.K.; Russell, K.F. Comparison of the rate of decomposition in $\mathrm{Fe}-45 \% \mathrm{Cr}, \mathrm{Fe}-45 \% \mathrm{Cr}-5 \% \mathrm{Ni}$ and duplex stainless steels. Appl. Surf. Sci. 1996, 94-95, 398-402. [CrossRef]

10. Westraadt, J.E.; Olivier, E.J.; Neethling, J.H.; Hedström, P.; Odqvist, J.; Xu, X.; Steuwer, A. A high-resolution analytical scanning transmission electron microscopy study of the early stages of spinodal decomposition in binary Fe-Cr. Mater. Charact. 2015, 109, 216-221. [CrossRef]

11. Zhou, J.; Odqvist, J.; Ågren, J.; Ruban, A.; Thuvander, M.; Xiong, W.; Olson, G.B.; Hedström, P. Direct atom probe tomography observations of concentration fluctuations in Fe-Cr solid solution. Scr. Mater. 2015, 98, 13-15. [CrossRef]

12. Suzudo, T.; Nagai, Y.; Schwenc, D.; Caro, A. Hardening in thermally-aged Fe-Cr binary alloys: Statistical parameters of atomistic configuration. Acta Mater. 2015, 89, 116-122. [CrossRef]

13. Li, Y.S.; Zhu, H.; Zhang, L.; Cheng, X.L. Phase decomposition and morphology characteristic in thermal aging Fe-Cr alloys under applied strain: A phase-field simulation. J. Nucl. Mater. 2012, 429, 13-18. [CrossRef]

14. Mukhamedov, B.O.; Ponomareva, A.V.; Abrikosov, I.A. Spinodal decomposition in ternary Fe-Cr-Co system. J. Alloys Compd. 2017, 695, 250-256. [CrossRef]

15. Li, Y.S.; Li, S.X.; Zhang, T.Y. Effect of dislocations on spinodal decomposition in Fe-Cr alloys. J. Nucl. Mater. 2009, 395, 120-130. [CrossRef]

16. Ustinovshikov, Y.; Shirobokova, M.; Pushkarev, B. A structural study of the Fe-Cr system alloys. Acta Mater. 1996, 44, 5021-5032. [CrossRef]

17. Ustinovshikov, Y.; Pushkarev, B. Morphology of Fe-Cr alloys. Mater. Sci. Eng. A 1998, 241, $159-168$. [CrossRef]

18. Chandra, D.; Schwartz, L.H. Mössbauer effect study of the $475^{\circ} \mathrm{C}$ decomposition of Fe-Cr. Metall. Trans. A 1971, 2, 2511-2519. [CrossRef]

19. Fratzl, P.; Penrose, O.; Weinkamer, R.; Žižak, I. Coarsening in the Ising model with vacancy dynamics. Physica A 2000, 279, 100-109. [CrossRef]

20. Cahn, J.W. The 1967 institute of metals lecture, spinodal decomposition. Trans. Met. Soc. AIME 1968, 242, 166-180.

21. Xiong, W.; Selleby, M.; Chen, Q.; Odqvist, J.; Du, Y. Phase equilibria and thermodynamic properties in the Fe-Cr system. Crit. Rev. Solid State Mater. Sci. 2010, 35, 125-152. [CrossRef]

22. Xiong, W.; Hedström, P.; Selleby, M. An improved thermodynamic modeling of the Fe-Cr system down to zero Kelvin coupled with key experiments. Calphad 2011, 35, 355-366. [CrossRef]

23. Pareige, C.; Roussel, M.; Novy, S.; Kuksenko, V.; Olsson, P.; Domain, C.; Pareige, P. Kinetic study of phase transformation in a highly concentrated Fe-Cr alloy: Monte Carlo simulation versus experiments. Acta Mater. 2011, 59, 2404-2411. [CrossRef]

24. Miller, M.K.; Hyde, J.M.; Hetherington, M.G.; Cerezo, A.; Smith, G.D.W.; Elliott, C.M. Spinodal decomposition in Fe-Cr alloys: Experimental study at the atomic level and comparison with computer models-I. introduction and methodology. Acta Metall. Mater. 1995, 43, 3385-3401. [CrossRef]

25. Hyde, J.M.; Miller, M.K.; Hetherington, M.G.; Cerezo, A.; Smith, G.D.W.; Elliott, C.M. Spinodal decomposition in Fe-Cr Alloys: Experimental study at the atomic level and comparison with computer models-II. development of domain size and composition amplitude. Acta Metall. Mater. 1995, 43, 3403-3413. [CrossRef]

26. Hyde, J.M.; Miller, M.K.; Hetherington, M.G.; Cerezo, A.; Smith, G.D.W.; Elliott, C.M. Spinodal decomposition in Fe-Cr alloys: Experimental study at the atomic level and comparison with computer models-III. development of morphology. Acta Metall. Mater. 1995, 43, 3415-3426. [CrossRef]

27. Lifshitz, I.M.; Slyozov, V.V. The kinetics of precipitation from supersaturated solid solutions. J. Phys. Chem. Solids 1961, 19, 35-50. [CrossRef]

28. Wagner, C. Theorie der alterung von niederschägen durch umlösen (Ostwald-Reifung). Z. Electrochem. 1961, 65, 581-591.

29. Rogers, T.M.; Elder, K.R.; Desai, R.C. Numerical study of the late stages of spinodal decomposition. Phys. Rev. B 1988, 37, 9638. [CrossRef]

30. Liu, W.; Li, Y.S.; Wu, X.C.; Hou, Z.Y.; Hu, K. Phase-field simulation of the separation kinetics of a nanoscale phase in a Fe-Cr alloy. J. Mater. Eng. Perform. 2016, 25, 1924-1930. [CrossRef]

31. Steinbach, I. Phase-field models in materials science. Model. Simul. Mater. Sci. Eng. 2009, 17, 073001. [CrossRef] 
32. Yeddu, H.K.; Malik, A.; Ågren, J.; Amberg, G.; Borgenstam, A. Three-dimensional phase-field modeling of martensitic microstructure evolution in steels. Acta Mater. 2012, 60, 1538-1547. [CrossRef]

33. Cahn, J.W. On spinodal decomposition. Acta Metall. 1961, 9, 795-801. [CrossRef]

34. Mohanty, R.R.; Guyer, J.E.; Sohn, Y.H. Diffusion under temperature gradient: A phase-field model study. J. Appl. Phys. 2009, 6, 034912. [CrossRef]

35. Andersson, J.O.; Ågren, J. Models for numerical treatment of multicomponent diffusion in simple phases. J. Appl. Phys. 1992, 72, 1350-1355. [CrossRef]

36. Japan Institute of Metals. Metals Data Book; Maruzen: Tokyo, Japan, 1993.

37. Koyama, T.; Onodera, H. Modeling of microstructure changes in Fe-Cr-Co magnetic alloy using the phase-field method. J. Phase Equilib. Diffus. 2006, 27, 22-29. [CrossRef]

38. Moelans, N. A quantitative and thermodynamically consistent phase-field interpolation function for multi-phase systems. Acta Mater. 2011, 59, 1077-1086. [CrossRef]

39. Cahn, J.W. Phase separation by spinodal decomposition in isotropic system. J. Chem. Phys. 1965, 42, 93-99. [CrossRef]

40. Andersson, J.O.; Sundman, B. Thermodynamic properties of the Cr-Fe system. Calphad 1987, 11, 83-92. [CrossRef]

41. Dinsdale, A.T. SGTE data for pure elements. Calphad 1991, 15, 317-425. [CrossRef]

42. Miiller, F.; Kubaschewski, O. The thermodynamic properties and equilibrium diagram of the system $\mathrm{Cr}-\mathrm{Fe}$. High Temp. High Press. 1969, 1, 543-551.

43. Cahn, J.W.; Hilliard, J.E. Free energy of a non-uniform system. 1. Interfacial free energy. J. Chem. Phys. 1958, 28, 258-267. [CrossRef]

44. Lass, E.A.; Johnson, W.C.; Shiflet, G.J. Correlation between CALPHAD data and the Cahn-Hilliard gradient energy coefficient $k$ and exploration into its composition dependence. Calphad 2006, 30, 42-52. [CrossRef]

45. Khachaturyan, A.G. Theory of Structure Transformation in Solids; John-Wiley and Sons: New York, NY, USA, 1983.

46. Hu, S.Y.; Chen, L.Q. A phase-field model for evolving microstructures with strong elastic inhomogeneity. Acta Mater. 2001, 49, 1879-1890. [CrossRef]

47. Zhu, J.Z.; Chen, L.Q. Coarsening kinetics from a variable-mobility Cahn-Hilliard equation: Application of a semi-implicit Fourier spectral method. Phys. Rev. E 1999, 60, 3564. [CrossRef]

48. Zhu, J.Z. Phase-Field Modeling Microstructural Evolution and Properties. Ph.D. Thesis, Pennsylvania State University, State College, PA, USA, 2002.

49. Brandes, E.A.; Brook, G.B. Smithells Metals Reference Book, 7th ed.; Butterworth-Heinemann: Oxford, UK, 1992.

50. Dever, D.J. Temperature dependence of the elastic constants in $\alpha$-iron single crystals: Relationship to spin order and diffusion anomalies. J. Appl. Phys. 1972, 43, 3293-3301. [CrossRef]

51. Katahara, K.; Nimalendran, M.; Manghnani, M.H.; Fisher, E.S. Elastic moduli of paramagnetic chromium and Ti-V-Cr alloys. J. Phys. F 1979, 9, 2167-2176. [CrossRef]

52. Li, Y.L.; Hu, S.Y.; Zhang, L.; Sun, X. Non-classical nuclei and growth kinetics of Cr precipitates in FeCr alloys during ageing. Model. Simul. Mater. Sci. Eng. 2014, 22, 025002. [CrossRef]

53. Heo, T.W.; Zhang, L.; Du, Q.; Chen, L.Q. Incorporating diffuse-interface nuclei in phase-field simulations. Scr. Mater. 2010, 63, 8-11. [CrossRef]

54. Zhang, L.; Ren, W.Q.; Samanta, A.; Du, Q. Recent developments in computational modelling of nucleation in phase transformations. NPJ Comput. Mater. 2016, 2, 16003. [CrossRef]

55. Lopez-Hirata, V.M.; Soriano-Vargas, O.; Rosales-Dorantes, H.J.; Saucedo-Muñoz, M.L. Phase decomposition in an Fe-40 at.\% Cr alloy after isothermal aging and its effect on hardening. Mater. Charact. 2011, 62, 789-792. [CrossRef]

56. Mao, Z.G.; Sudbrack, C.K.; Yoon, K.E.; Martin, G.; Seidman, D.N. The mechanism of morphogenesis in a phase-separating concentrated multicomponent alloy. Nat. Mater. 2007, 6, 210-216. [CrossRef] [PubMed]

57. Brenner, S.S.; Miller, M.K.; Sofia, W.A. Spinodal decomposition of iron-32 at. $\%$ chromium at $470{ }^{\circ}$ C. Scr. Metall. 1982, 16, 831-836. [CrossRef] 
58. Bley, F. Neutron small-angle scattering study of unmixing in Fe-Cr alloys. Acta. Metall. Mater. 1992, 40, 1505-1517. [CrossRef]

59. Lasalle, J.C.; Schwartz, L.H. Further studies of spinodal decomposition in Fe-Cr. Acta Metall. 1986, 34, 989-1000. [CrossRef]

60. Yan, Z.L.; Li, Y.S.; Zhou, X.R.; Zhang, Y.D.; Hu, R. Evolution of nanoscale Cr-rich phase in a Fe-35 at.\% Cr alloy during isothermal aging. J. Alloys Compd. 2017, 725, 1035-1043. [CrossRef]

(c) (1) 